\title{
Comparison of the Revenue Situation in Interventional \\ Radiology Based on the Example of Peripheral Artery Disease in the Case of a DRG Payment System and Various Internal Treatment Charges
}

\author{
Vergleich der Erlössituation in der interventionellen \\ Radiologie am Beispiel der peripheren arteriellen \\ Verschlusskrankheit bei Anwendung eines DRG- \\ Gesamterlösmanagements und verschiedener \\ innerbetrieblicher Leistungsverrechnungen
}

Authors

Florian M. Vogt, Peter Hunold, Julian Haegele, Erik Stahlberg, Jörg Barkhausen, Jan Peter Goltz

Affiliation

Clinic for Radiology and Nuclear Medicine, University Hospital

of Schleswig-Holstein, Campus Lübeck, Germany

Key words

cost-effectiveness, health policy and practice, interventional procedures, DRG, internal treatment charges

received 17.12.2016

accepted 19.09.2017

Bibliography

DOI https://doi.org/10.1055/s-0043-121471

Published online: 1.3.2018

Fortschr Röntgenstr 2018; 190: 348-357

(c) Georg Thieme Verlag KG, Stuttgart · New York

ISSN 1438-9029

Correspondence

Priv.-Doz. Dr. Jan Peter Goltz

Clinic for Radiology and Nuclear Medicine,

University Hospital of Schleswig-Holstein, Campus Lübeck,

Ratzeburger Allee 160, 23538 Lübeck, Germany

Tel.: ++ 49/451/50017015

Fax: ++49/4 51/50017004

JanPeter.Goltz@uksh.de

\section{ABSTRACT}

Purpose Calculation of process-orientated costs for inpatient endovascular treatment of peripheral artery disease (PAD) from an interventional radiology (IR) perspective. Comparison of revenue situations in consideration of different ways to calculate internal treatment charges (ITCS) and diagnosis-related groups (DRG) for an independent IR department.

Materials and Methods Costs (personnel, operating, material, and indirect costs) for endovascular treatment of PAD patients in an inpatient setting were calculated on a full cost ba- sis. These costs were compared to the revenue situation for IR for five different scenarios: 1) IR receives the total DRG amount. IR receives the following DRG shares using ITCS based on InEK shares for 2) "Radiology" cost center type, 3) "OP" cost center type, 4) "Radiology" and "OP" cost center type, and 5) based on DKG-NT (scale of charges of the German Hospital Society).

Results 78 patients (mean age: $68.6 \pm 11.4 \mathrm{y}$ ) with the following DRGs were evaluated: F59A $(n=6)$, F59B $(n=14)$, F59C $(n=20)$ and F59D $(n=38)$. The length of stay for these DRG groups was $15.8 \pm 12.1,9.4 \pm 7.8,2.8 \pm 3.7$ and $3.4 \pm 6.5$ days Material costs represented the bulk of all costs, especially if new and complex endovascular procedures were performed. Revenues for neither InEK shares nor ITCs based on DKG-NT were high enough to cover material costs. Contribution margins for the five scenarios were $1=€ 1,539.29,2=€-1,775.31$, $3=€-2,579.41,4=€-963.43,5=€-2,687.22$ in $F 59 A$, $1=€-792.67,2=€-2,685.00,3=€-2,600.81,4=€-1,618.94$, $5=€-3,060.03$ in $\mathrm{F} 59 \mathrm{~B}, 1=€-879.87,2=€-2,633.14$, $3=€-3,001.07,4=€-1,952.33,5=€-3,136.24$ in $\mathrm{F} 59 \mathrm{C}$ and $1=€ 703.65, \quad 2=€-106.35, \quad 3=€-773.86, \quad 4=€ 205.14$, $5=€-647.22$ in F59D. InEK shares return on average $€ 150$ - 500 more than ITCs based on the DKG-NT catalog.

Conclusion In this study positive contribution margins were seen only if IR receives the complete DRG amount. InEK shares do not cover incurred costs, with material costs representing the main part of treatment costs. Internal treatment charges based on the DKG-NT catalog provide the worst cost coverage.

\section{Key points}

- Internal treatment charges based on the DKG-NT catalog provide the worst cost coverage for interventional radiology at our university hospital.

- Shares from the InEK matrix such as the cost center "radiology" or "OP" as revenue for IR are not sufficient to cover 
incurred costs. A positive contribution margin is achieved only in the case of a compensation method in which IR receives the total DRG amount.

\section{Citation Format}

- Vogt FM, Hunold P, Haegele J et al. Comparison of the Revenue Situation in Interventional Radiology Based on the Example of Peripheral Artery Disease in the Case of a DRG Payment System and Various Internal Treatment Charges. Fortschr Röntgenstr 2018; 190: 348-357

\section{ZUSAMMENFASSUNG}

Ziel Ermittlung prozessorientierter Kosten für die stationäre endovaskuläre Behandlung der peripheren arteriellen Verschlusskrankheit (pAVK) aus Perspektive der interventionellen Radiologie (IR). Gegenüberstellung der Erlössituation unter Berücksichtigung verschiedener Prinzipien der internen Leistungsverrechnung („ILV“) sowie einer eigenständigen IR unter DRG-Bedingungen.

Material und Methoden Für den Prozess endovaskulärer Behandlung der pAVK im stationären Bereich erfolgte nach Entwicklung der Prozessbeschreibung eine prozessorientierte Berechnung der Kosten (Personal-, Betriebs-, Material- und Gemeinkosten) auf Vollkostenbasis. Die so ermittelten Prozesskosten wurden der Erlössituation für die IR unter Annahme von fünf Szenarien gegenübergestellt: 1) IR erlöst die gesamte DRG-Fallpauschale. IR erlöst durch interne Leistungsverrechnung in Anlehnung an die Kostenmatrix des Instituts für das Entgeltsystem im Krankenhaus (InEK) folgende DRGAnteile 2) nach Kostenstellenart Radiologie 3) nach Kostenstellenart OP 4) nach Kostenstellenart OP und Radiologie oder 5) in Anlehnung an den Gebührenkatalog der DKG-NT (Tarifwerk der Deutschen Krankenhausgesellschaft).

Ergebnisse Es wurden 78 Patienten (mittleres Alter 68,6 $\pm 11,4$ Jahre) mit folgenden DRGs ausgewertet: F59A ( $n=6)$, F59B $(n=14)$, F59C $(n=20)$ und F59D $(n=38)$. Die Verweildauer für diese DRG Gruppen betrug 15,8 $\pm 12,1,9,4 \pm 7,8$, 2,8 \pm 3,7 und 3,4 \pm 6,5 Tage. Die Materialkosten bildeten den Großteil der Kosten, vor allem bei Einsatz der neuesten und kompliziertesten endovaskulären Behandlungsverfahren. Weder die Erlöse aus den InEk-Anteilen und insbesondere nicht die Erlöse aus der ILV nach DKG-NT reichen im Durchschnitt aus, um die eingesetzten Materialien in ihren reinen Anschaffungskosten zu decken. Die Deckungsbeiträge für die fünf Szenarien betrugen in F59A ( $1=1539,29 €, 2=-1775,31 €$, $3=-2579,41 €, \quad 4=-963,43 €, \quad 5=-2687,22 €), \quad$ F59B $(1=-792,67,2=-2685,00 €, 3=-2600,81 €, 4=-1618,94 €$, $5=-3060,03 € €)$, F59C $(1=-879,87 €, 2=-2633,14 €$, $3=-3001,07 €, 4=-1952,33 €, 5=-3136,24 €)$ und F59 $D$ $(1=703,65 €, 2=-106,35 €, 3=-773,86 €, 4=205,14 €$, $5=-647,22 €)$. InEK-Anteile erlösen gegenüber der ILV in Anlehnung an den Gebührenkatalog der DKG-NT im Durchschnitt $150-500 €$ mehr.

Schlussfolgerung Positive Deckungsbeiträge kann die IR im untersuchten Setting nur erlösen, wenn sie den Gesamterlös der DRG-Fallpauschale erhält. Teilpauschalen aus der InEKMatrix reichen nicht aus, um anfallende Kosten zu decken, wobei Materialkosten den Großteil der Behandlungskosten bilden. Den schlechtesten Deckungsbeitrag liefert die ILV in Anlehnung an den DKG-NT Katalog.

\section{Introduction}

With a prevalence of $5-10 \%$ of the population in Germany, peripheral artery disease (PAD) is exceedingly common and an increase of $30 \%$ by 2030 can be expected [1]. The prevalence of PAD increases significantly with age: $19.8 \%$ of men and $16.8 \%$ of women over the age of 65 in Germany [2]. PAD is currently number one among treatment costs for all cardiovascular diseases (35.2 billion Euros) [3]. Endovascular treatment of PAD has continuously developed in recent years and is often preferred over open surgical treatment since it achieves similar results while being less invasive and more cost-efficient [4]. The restructuring of the hospital reimbursement system on the basis of diagnosisrelated groups (DRGs) has resulted in comprehensive structural changes in most hospitals.

Prior to the introduction of DRGs, radiologists generally had the ability to independently acquire and treat patients with this disease. However, since radiology departments are often integrated in patient care on a decentralized, interdisciplinary basis as a department without its own beds (cost center), radiological-interventional procedures are performed as an (internal) service for referring departments in such a scenario. The referring departments receive the DRG payment while the radiology department as the provider of the main service receives payment for internal treatment charges.

Internal treatment charges can be fundamentally different, e. g. calculated in radiology as its own cost center based on medical fee schedule point values individually determined for the hospital based on existing fee catalogs, fixed prices for certain services or combinations of service and material cost shares, such as in the cost matrix of the Institute for the Hospital Remuneration System (InEK) for calculating DRGs.

For interventional radiology using medical fee schedule-based internal treatment charges, a large number of costly interventions can be disadvantageous since ITCs are derived from internal budgeting and internal budgeting is derived from the cap of the total hospital budget. The budget of the radiology department is based on the expected costs of planned services. However, the volume of services cannot be arbitrarily increased by increasing the number of points. Given a fixed total volume of the personnel and materials budget, an increase in the number of points only results in a corresponding reduction in the monetary point value. Moreover, when considering radiology as a cost center, increasing medical fee schedule point costs in a large proportion of interventional-radiological interventions can result in a worse performance in comparison with other radiology departments (e. g. with a low propor- 
tion of such interventions). The situation is slightly different when actual revenues for the treatment cases are allocated based on medical fee schedule codes (there is no true budget cap for clinics). However, it must be taken into consideration here that adjustments for additional profits can affect increases in services beyond the final budget.

An internal discussion between controlling, interventional radiology, and other departments involved in endovascular procedures may then even result in endovascular services being completely transferred to a department with beds or receiving DRG payment in some hospitals in order to allow simpler balancing of department earnings, possibly without taking expertise into consideration.

Also in other ITC procedures such as payment from InEK shares, interventional radiology often receives only shares of the case payments that do not cover costs, even though the department bears the costs for personnel, the angiography system, and in particular materials, with the exception of ward costs and a few consultation service costs. It must be noted in relation to the angiography system that at least the procurement costs are not eligible to be reimbursed via daily treatment rates and thus there is no compensation from the InEK matrix. They must thus be otherwise financed as investment costs and are not to be included in the ITC model calculation.

In such a model the radiology clinic is dependent on the referring departments and has minimal influence over the revenue situation on the one hand [5]. On the other hand, actually incurred costs are often not identified owing to insufficient and complex process cost accounting: controlling of costs and consumption of resources via annual budgeting is only possible on a limited basis for the service provider. This limits the efficient management of an interventional radiology department. It is particularly difficult when the radiology clinic is supposed to make a balanced or positive contribution under the conditions of internal treatment charges in a multi-level contribution margin accounting system.

Accordingly, it would potentially be desirable for radiology to receive payments that are separate from internal treatment charges while maintaining the option of controlling costs and consumption of resources.

The goal of this study is to determine process-oriented real costs for endovascular treatment of PAD from the perspective of interventional radiology and present the contribution margin for radiology based on five different revenue models.

\section{Materials and Methods}

Peripheral vascular interventions are usually performed on an inpatient basis. Since the beginning of 2015, patients in whom primary endovascular treatment was planned have received inpatient care from medical and non-medical personnel in vascular surgery, with DRG payments being allocated to radiology as the organizational unit performing the treatment.

\section{Patients and study period}

All patients who underwent endovascular treatment of the vessels of the pelvis and lower extremities due to PAD at the clinic for radiology and nuclear medicine between $1 / 1 / 2015$ and $5 / 31 / 2015$ were recorded and all radiological activities including the persons involved, the duration of the activity, and the materials used were documented in detail. Moreover, activities performed during the treatment process by other departments on behalf of radiology were documented.

\section{Calculations regarding the revenue situation}

1. Total payment for a particular DRG

Using a DRG grouper, internal hospital controlling performed G-DRG coding according to F59A-D for the different angiographic interventions on the basis of the OPS and ICD-10 codes $(\triangleright$ Table 1$)$. The OPS codes used most frequently are listed in - Table 2.

Controlling then calculated the effective total payment for the particular treatment cases depending on secondary diagnoses, patient-based case severity codes, length of stay, and any supplementary payments, NUB and DRG surcharges. The basic case price in Schleswig-Holstein for 2015 of $€ 3190.81$ was used as a basis.

Since endovascular treatment was primarily performed by the radiology clinic connected to a certified vascular center at this time in our university hospital, it also received the total payment for the particular DRG code. However, since inpatient care and hospitalization were still performed by the vascular surgery department, radiology was responsible for the daily rate for the beds provided including the inpatient care costs in this setting on a full cost basis. The radiology clinic was charged a flat rate of 205.00 Euros per day for bed use in the vascular surgery department on a full cost basis. The sum includes nursing costs, medical service, food, bandages, and medication, secretarial services, room rental, and indirect costs. Additional services purchased by radiology, such as lab costs, were reimbursed as part of internal treatment charges based on the medical fee schedule point system as explained in greater detail below.

A further classification based on the selected internal treatment charge method was performed in a second calculation investigating potentially achievable revenues in an environment in which radiological-interventional procedures are performed as a service for referring clinics. To determine a hypothetical payment, fictitious revenues were calculated separately for the following scenarios.

2. Partial DRG revenue (InEK cost center type 9: Radiology) under the assumption that the radiology clinic performs endovascular treatment in an interdisciplinary setting and radiology receives only partial DRG revenue for the cost center type "radiology".

3. Partial DRG revenue (InEK cost center type 4: OP) under the assumption that the radiology clinic performs endovascular treatment in an interdisciplinary setting and radiology receives only partial DRG revenue for the cost center type "OP".

4. Partial DRG revenue (InEK cost center types 9 and 4: Radiology and $\mathrm{OP}$ ) under the assumption that the radiology clinic performs endovascular treatment in an interdisciplinary setting and receives partial DRG revenue for the cost center type "OP" 
- Table 1 DRG codes for PAD interventions

\begin{tabular}{|c|c|c|c|}
\hline F59A & F59B & F59C & F59 D \\
\hline $\begin{array}{l}\text { complex vascular interventions } \\
\text { without a complicating constel- } \\
\text { lation, without revision, without } \\
\text { a complicating diagnosis, age } \\
\text { > } 2 \text { years, without certain bilat- } \\
\text { eral vascular interventions, with } \\
\text { extremely serious CC, or mod- } \\
\text { erately complex vascular inter- } \\
\text { ventions with extremely serious } \\
\text { CC or rotational thrombectomy. }\end{array}$ & $\begin{array}{l}\text { moderately complex vascular } \\
\text { interventions or complex vascu- } \\
\text { lar interventions without a com- } \\
\text { plicating constellation, without } \\
\text { revision, without a complicating } \\
\text { diagnosis, age > } 2 \text { years, without } \\
\text { existing bilateral vascular inter- } \\
\text { ventions, without extremely } \\
\text { serious CC, without rotational } \\
\text { thrombectomy, with complica- } \\
\text { ted interventions or existing di- } \\
\text { agnosis or age < } 16 \text { years }\end{array}$ & $\begin{array}{l}\text { moderately complex vascular } \\
\text { interventions or complicated } \\
\text { vascular interventions without a } \\
\text { complicating constellation, } \\
\text { without revision, without a } \\
\text { complicating diagnosis, age } \\
>2 \text { years, without existing bilat- } \\
\text { eral vascular interventions, } \\
\text { without extremely serious CC, } \\
\text { without rotational thrombect- } \\
\text { omy, without complicated in- } \\
\text { terventions, without existing } \\
\text { diagnosis age }>15 \text { years, with } \\
\text { existing interventions }\end{array}$ & $\begin{array}{l}\text { moderately complex vascular in- } \\
\text { terventions or complex vascular } \\
\text { interventions without a compli- } \\
\text { cating constellation, without re- } \\
\text { vision, without a complicating } \\
\text { diagnosis, age }>2 \text { years, without } \\
\text { existing bilateral vascular inter- } \\
\text { ventions, without extremely } \\
\text { serious CC, without rotational } \\
\text { thrombectomy, without compli- } \\
\text { cated interventions, without ex- } \\
\text { isting diagnosis, age }>15 \text { years, } \\
\text { without existing interventions }\end{array}$ \\
\hline
\end{tabular}

- Table 2 Frequently used OPS codes

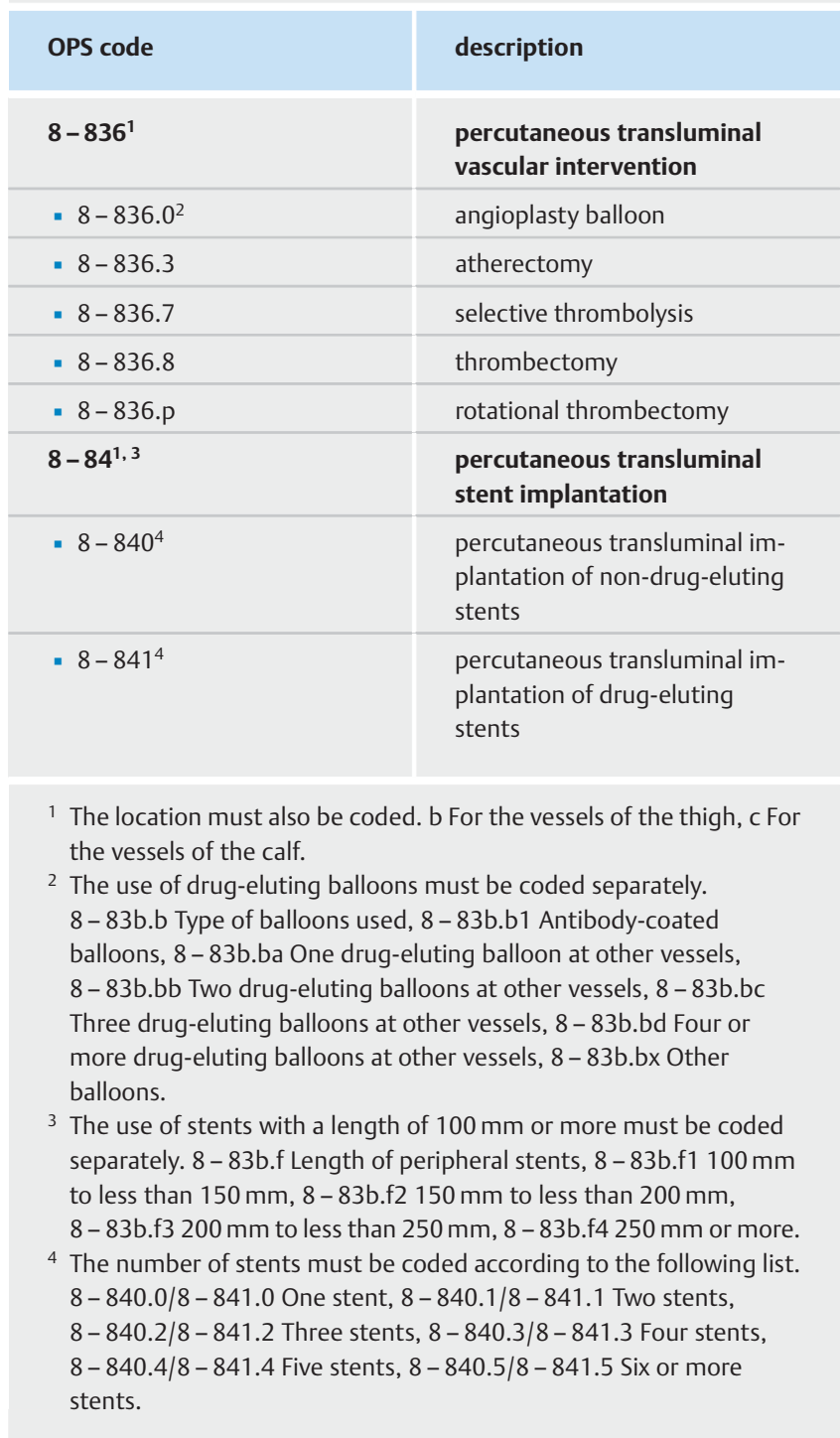

in addition to partial DRG revenue for the cost center type "radiology".

5. Internal treatment charges based on the DKG-NT catalog under the assumption that the radiology clinic as the service provider is performing the endovascular treatment and is compensated for the point values based on a defined point value according to the billed services.

\section{Internal treatment charges based on G-DRG partial payments}

InEK applies a standardized modular structure to calculated case costs for each treatment case. The individual cost modules are defined by both a cost type and a cost center reference. This results in a matrix structure of the cost centers for each DRG code (see Table 3 - example F59A):

- Cost center group 1: General ward

- Cost center group 2: Intensive care unit

- Cost center group 3: Dialysis department

- Cost center group 4: Surgical department

- Cost center group 5: Anesthesiology

- Cost center group 6: Delivery room

- Cost center group 7: Cardiology diagnosis/treatment

- Cost center group 8: Endoscopic diagnosis/treatment

- Cost center group 9: Radiology

- Cost center group 10: Labs

- Cost center group 11:

Other diagnostic and therapeutic areas

Assuming an interdisciplinary approach in the radiology clinic performing endovascular treatment, only the cost shares for the cost center "radiology" were allocated to the radiology department in a first approach as payment. In a second approach, the cost shares for the cost centers "radiology" and "OP" from the InEK matrix were allocated to radiology as a partial payment. This was performed under the assumption that interventional treatment in these cases corresponds to "OP service" and thus to the OP share of this DRG amount. 


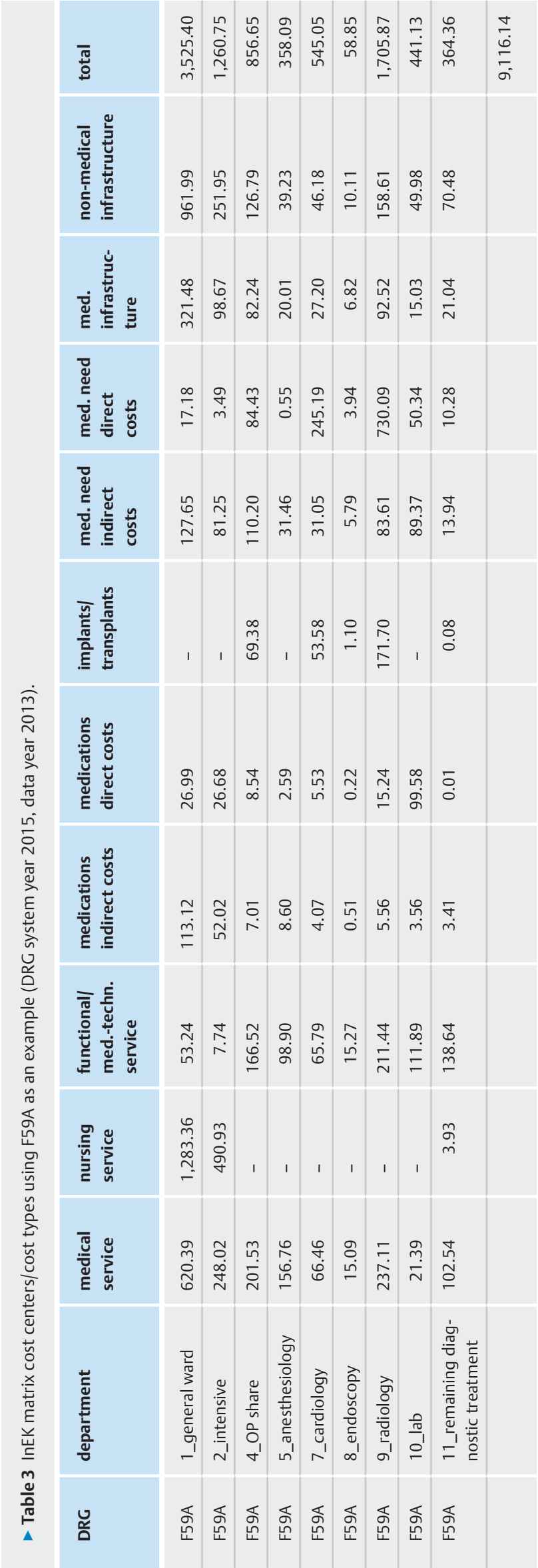

\section{Internal treatment charges based on DKG-NT}

The RIS used by us (Orbis, Agfa) provides all corresponding medical fee schedule codes according to the billed services. There are equivalents for the individual medical fee schedule codes in an internal hospital catalog that are closely based on the DKG-NT. In our hospital, internal treatment charges are based on these service codes. Regular control adjusts the point value to price and service development in connection with the internal treatment charges. The value was 0.0365 cents/point in 2015 for radiological services. The compensation amount is determined by multiplying the number of points by the point value.

This comparative calculation is used to show the difference in contribution margin amounts resulting from interventional-radiological vascular interventions under different basic conditions.

\section{Calculations regarding the cost situation}

To calculate the profit and loss situation of revenues generated from DRGs and ITCs, the cost calculation was performed as full costing corresponding to direct costs (personnel/material costs) plus indirect costs of the hospital.

\section{Personnel costs for medical and medical-technical service}

To calculate the cost of wages ( 1 head physician and 1 assistant physician, 1 radiographer) including ancillary wage costs, minute rates according to the average personnel costs of our hospital were used (head physician: 1.31 Euros/min., assistant physician: 0.70 Euros/min., radiographer: 0.57 Euros/min.) The personnel costs were calculated as the average time spent with a patient per intervention (duration of procedure incl. preparation time, manual compression, compression bandage and examination documentation, home-to-office time, parallel supervision of work stations, time for reporting and meetings).

\section{Material and operating costs for angiography}

A standardized procedure is used for the interventions evaluated in this study so that the material costs can be easily calculated for all relevant angiographic procedures. The unit costs (including VAT and any discounts) were determined on the basis of the individual materials used. The material cost list (as of May 2015) of central controlling of our hospital was used as the database for research. The material costs for each intervention were determined using this list. A flat rate of $€ 36.69$ was calculated for each item needed for an intervention. This includes a wash set, an angiography set (sterile patient cover/tubes, two aprons, syringes, various needles, compresses, scalpel, container for contrast agent and saline, temporary storage of catheters) and an insertion cannula with a special cut and two-way stopcocks for connecting the catheters with the contrast agent pump.

The operating costs for angiography were calculated according to the duration of the intervention and include device operation, electricity costs, maintenance costs, room costs including cleaning. The hospital's usual average of 2100 operating hours was used for the angiography system. The operating costs were con- 


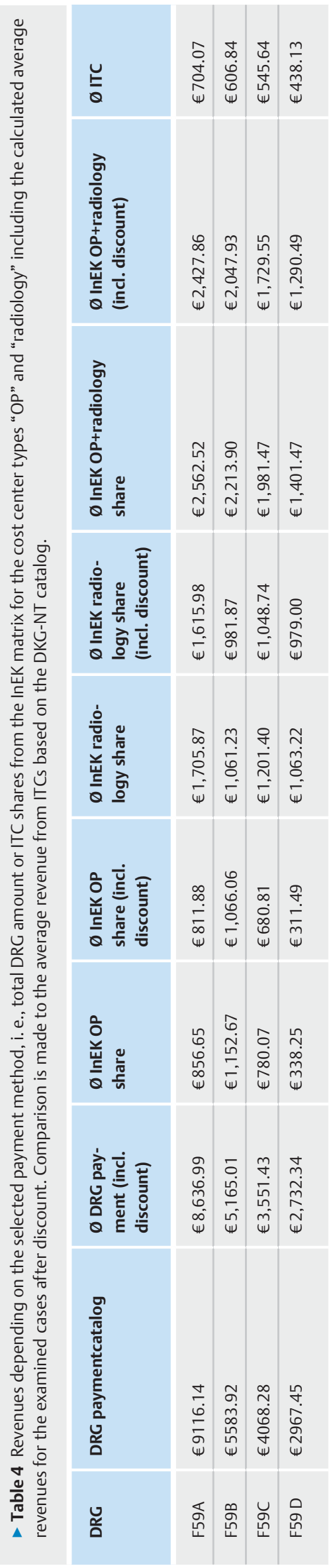

verted to the average procedure time for each angiographic intervention.

\section{ITCs for radiology as discharging department}

Individual activities in the main processes are not performed by radiology but are purchased by other departments and integrated in the total process. This relates, for example, to ECG examinations or lab services. The costs for these activities were calculated as part of the internal treatment charges by hospital management on a full cost basis.

\section{Indirect costs}

Indirect costs were set at $24 \%$ for our hospital in 2014 and are applied to personnel, angiography operation, and material costs. They include the costs for the general management of the personnel department and financial accounting, patient management, economic services, and other operating costs.

\section{Calculations regarding the profit and loss situation}

Depending on the approach for the particular treatment, the process costs calculated in this manner were compared to the above-described revenue situations on a full (radiology receives entire DRG payment) or partial basis (radiology as service provider receives internal treatment charges based on DKG-NT or in the form of InEK shares).

Radiology worked as a service provider at our university hospital until the end of 2014. The incurred personnel, material and operating costs were included in internal treatment charges on the basis of the volume of services defined at the start of the year in target meetings. For this reason, these items were fully included in the cost calculation for the exemplary calculations performed here for contribution margins in the ITC setting (DKG-NT and InEK shares). The following items were not included in the cost calculations for a service provider: ward costs and the ITCs for radiology as the discharging department including the share of indirect costs.

\section{Results}

78 patients (48 men (61.5\%), 30 women (38.5\%)) were examined in the study period. The average patient age was $68.6+/-11.4$ years. F59A $(n=6)$, F59B $(n=14)$, F59C $(n=20)$ and F59D $(n=38)$ were coded. The average length of stay was $15.8 \pm 12.1$ days for F59A, 9.4 \pm 7.8 for F59B, $2.8 \pm 3.7$ for F59C and 3.4 \pm 6.5 for F59 D.

\section{Revenues}

The revenues to be achieved for DRG cases F59A-D are compared in $>$ Table 4 as a function of the selected calculation method. As expected, the revenues to be achieved are highest when the radiology clinic receives the entire DRG amount. However, discounts compared to catalog revenues must be expected in the case of interventional-radiological treatment due to the shorter length of stay resulting in the minimum length of stay requirement not being met. This relates primarily to F59 D cases. The minimum 
- Table 5 Revenues from shares for the cost center types "radiology" and "OP" from the InEK cost matrix.

\begin{tabular}{|c|c|c|c|c|c|c|c|}
\hline & revenues & InEK share "OP" & in \% & InEK share "radiology" & in $\%$ & total OP+radiology & in $\%$ \\
\hline F59A & $€ 9,116.14$ & $€ 856.65$ & $9.40 \%$ & $€ 1,705.87$ & $18.71 \%$ & $€ 2,562.52$ & $28.11 \%$ \\
\hline F59B & $€ 5,583.92$ & $€ 1,152.67$ & $20.64 \%$ & $€ 1,061.23$ & $19.01 \%$ & $€ 2,213.90$ & $39.65 \%$ \\
\hline F59C & $€ 4,068.28$ & $€ 780.07$ & $19.17 \%$ & $€ 1,201.40$ & $29.53 \%$ & $€ 1,981.47$ & $48.71 \%$ \\
\hline F59D & $€ 2,967.45$ & $€ 338.25$ & $11.40 \%$ & $€ 1,063.22$ & $35.83 \%$ & $€ 1,401.47$ & $47.23 \%$ \\
\hline
\end{tabular}

length of stay is two days (admission and discharge day $=1$ day of hospitalization) and 28 of a total of 38 cases were generated with discounts owing to the minimum length of stay requirement not being met (74\%). In the severe F59A cases, only one case was generated with a discount owing to the minimum length of stay requirement not being met. On average, a discount in the amount of $8.35 \%$ was calculated for all cases (F59A: 7.92\%; F59B 7.51\%; F59C $12.71 \%$; F59D $7.92 \%)$.

If only shares of the DRG amount based on the InEK cost matrix are taken into consideration, the InEK share "radiology" has a higher percentage of the total revenue compared to the InEK share "OP" with the exception of the F59B and this increases with a decrease in case complexity from F59A to F59D ( $\triangleright$ Table 5).

Compared to revenue calculated from internal treatment charges based on the DKG-NT catalog, shares from the "OP" cost center type is always preferable to ITCs based on DKG-NT. Remuneration that is $€ 126.64$ higher on average compared to "OP" shares can be achieved with ITCs based on DKG-NT only in F59 D cases ( $\triangleright$ Table 4 )

On the whole, InEK shares yield significantly higher returns than ITCs based on DKG-NT, resulting in an increase in revenue from $€ 150$ to $€ 500$. An increase in revenue of $€ 450$ to $€ 900$ can be achieved with the InEK share "radiology". Assuming that in the case of only interventional-radiological treatment in these cases the radiology clinic is entitled to the shares from the cost center type "radiology" and "OP", there is higher revenue generation of $69 \%$ on average for all case types (F59A-D) compared to ITCs based on DKG-NT (discounts already taken into consideration).

In general, the revenue from ITCs based on DKG-NT compared to the total DRG amount under consideration of discounts is between $8.15 \%$ (F59A) and $16.03 \%$ (F59D). The average is $12.82 \%$.

\section{Costs}

The costs incurred at our hospital for DRG codes F59A-D are listed in Table 6.

The material costs for an intervention show that, on average, the revenues from the "OP" share and the "radiology" share, and in particular the revenues from ITCs based on DKG-NT are not sufficient to cover the materials used at our hospital purely with respect to procurement costs. Only the InEK share "radiology" for $F 59 \mathrm{D}$ cases is high enough to cover the average material costs of these DRG cases.

The average material costs for DRG F59B are $51 \%$ of the DRG revenues and those of DRG F59C are even $74.5 \%$. It is also apparent that the material costs for DRG F59B and F59C fluctuate greatly and are highest in the case of DRG F59C ( $>$ Table 7). Material costs per case can range between $€ 207$ and $€ 8,885$. At least one bare metal stent was implanted in $57 \%$ of cases in the $\mathrm{F} 59 \mathrm{~B}$ group while $70 \%$ of patients in the $\mathrm{F} 59 \mathrm{C}$ group received at least one such stent. In addition, a drug-eluting PTA balloon (DEB) was used in one case in the F59B group, at least one stent graft was used in two cases (14\%), and a reentry catheter was used in four cases (29\%). At least one drug-eluting PTA balloon was used in three cases (15\%) in the F59C group and at least one stent graft was used in five cases ( $25 \%)$.

The fluctuations in material costs are also relatively high in the F59A group. This can be explained by the use of mechanical rotational thrombectomy catheters in 3 of 6 cases and the sole use of a DEB in one patient with the procurement costs being almost covered by supplementary payments in this case. The average costs constitute $27.9 \%$ of the DRG revenue in this case.

In the F59 D group, the fluctuations in material costs are around $€ 2000$ and are thus significantly lower compared to the groups F59A-C. In this case, the average material costs are also only $25 \%$ of the DRG revenues and are thus the lowest. In our F59 D patient group, a bare metal stent was implanted in $63 \%$ of the patients $(n=24)$, while a drug-eluting PTA balloon with or without subsequent stent implantation was used in $34 \%$ $(n=13)$.

\section{Contribution margins}

An overview of the resulting contribution margins of the treated F59A-D cases for the five scenarios is provided in $\mathbf{T a b l e ~} 8$. This results in a positive contribution margin only for F59A and F59D cases only when radiology receives the "radiology" and "OP" shares from the DRG payment (F59D) or receives the entire DRG payment as a department with beds. The reason for the at times very high negative contribution margins is an overproportion of material costs.

\section{Discussion}

The frequency of PAD is continuously increasing and the disease is relevant for cost development in the health care system [6]. Endovascular procedures have become increasingly established compared to surgical methods and will continue to increase in the future.

The goal of this study was to compare revenues to costs calculated by process cost accounting and to determine the extent to 


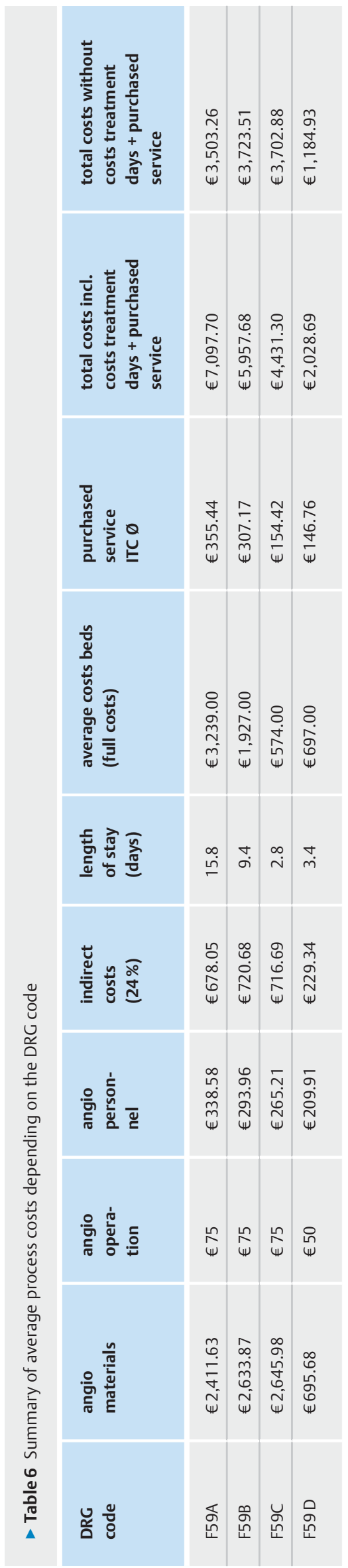

which different compensation scenarios can provide cost coverage for interventional radiology in the current revenue situation at a university hospital.

The results of this study show that the cost homogeneity assumed in the DRG system within individual groups is not realistic particularly for F59B and F59C, but a hospital radiology department in a university setting can achieve relevant revenues for the treatment of PAD under the DRG system (approx. 300,000 Euros for 78 F59A-D cases). In contrast to the revenue situation, the actual costs for endovascular procedures are not known or the data are not current $[5,7,8]$. Strotzer et al. were able to show already in 2002 that there are significant discrepancies between calculated costs and the internal treatment charges calculated according to the medical fee schedule and the DKG-NT [7]. Nolte-Ernsting et al. published data that seem to prove that PAD interventions performed on an inpatient basis are among the "winners" of all examined radiological interventions despite the high material costs [5]. However, the profit situation was greatly dependent on the particular materials used. Higher profits were only able to be achieved with low and efficient use of materials.

Our data show that a relevant increase in medical and material costs occurs outside of the F59 D group. However, greater use of materials in increasingly complex lesions is to be expected. Under consideration of the fixed DRG payment situation, an additionally implanted stent after PTA becomes a cost risk, particularly when a drug-eluting stent (DES) is used. This results in possible disincentives. Therefore when only the payment situation and not the clinical outcome are taken into consideration, it seems to make sense to use the smallest possible amount of materials rather than to achieve maximum benefit for the patient. However, current studies clearly prove, for example, that improved patency rates are achieved with the use of modern procedures (e. g., DEB, DES, BMS) compared to PTA alone [9]. Moreover, it is clear that material costs are already so high that on average ITCs from the "OP" share and from the "radiology" share of the InEK matrix and in particular payments from ITCs based on DKG-NT are not sufficient for cost coverage. Reference has already been made to the problem of variable costs, particularly in the form of material costs, in a similar setting [10]. Interestingly, material costs are relatively low at $27.9 \%$ of the total DRG amount particularly in the most severe cases (F59A). This can be explained in that these cases in particular yield a positive contribution margin when the entire DRG amount is received. The fact that new (and often more expensive materials) are only taken into consideration in the InEK cost matrix on a delayed basis seems problematic in this connection. An example of this is the implantation of a DES which does not result in (shares of) cost reimbursement either via NUB or supplementary payments and negatively affects the revenue situation. This is surprising since the use of a DES can result in lower total costs for PAD treatment than when, for example, a bare metal stent is used owing to the lower reintervention rates among other things [11].

The contribution margins simulated in $\mathbf{T a b l e} \mathbf{8}$ show that the high material costs in 4 of 5 evaluated compensation scenarios at our university hospital result in interventional radiology generally not being able to cover costs. A positive contribution margin is achieved only in the case of a compensation method in which 
- Table 7 Summary of material costs for angiography depending on the DRG code. Total costs and average costs for the individual DRG codes and the minimum and maximum material costs are specified.

overview of material costs for angiography

\begin{tabular}{|l|l|l|l|}
\hline & F59A & F59B & F59C \\
\hline number of cases & 6 & 14 & 20 \\
\hline total material costs & $€ 14,469.79$ & $€ 36,874.12$ & $€ 52,919.51$ \\
\hline average material costs & $€ 2,411.63$ & $€ 2,633.87$ & $€ 2,645.98$ \\
\hline minimum material costs & $€ 253.69$ & $€ 206.69$ & $€ 604.64$ \\
\hline maximum material costs & $€ 5,783.59$ & $€ 8,884.61$ & $€ 7,905.64$ \\
\hline
\end{tabular}

Table 8 Summary of average contribution margins depending on the DRG code.

\begin{tabular}{|l|l|l|l|l|l|l|}
\hline $\begin{array}{l}\text { DRG } \\
\text { code }\end{array}$ & $\begin{array}{l}\text { DB DRG pay- } \\
\text { ment (without } \\
\text { discount) }\end{array}$ & $\begin{array}{l}\text { DB ø DRG pay- } \\
\text { ment (incl. dis- } \\
\text { counts) }\end{array}$ & $\begin{array}{l}\text { DB ITC OP } \\
\text { share (incl. dis- } \\
\text { counts) }\end{array}$ & $\begin{array}{l}\text { DB ITC radiolo- } \\
\text { gy share (incl. } \\
\text { discounts) }\end{array}$ & $\begin{array}{l}\text { DB ITC OP+radiolo- } \\
\text { gy share (incl. dis- } \\
\text { counts) }\end{array}$ \\
\hline F59A & $€ 2,018.44$ & $€ 1,539.29$ & $€-2,579.41$ & $€-1,775.31$ & $€-963.43$ & $\begin{array}{l}\text { DB ITC } \\
\text { based on } \\
\text { DKG-NT }\end{array}$ \\
\hline F59B & $€-373.76$ & $€-792.67$ & $€-2,600.81$ & $€-2,685.00$ & $€-1,618.94$ & $€-2,687.22$ \\
\hline F59C & $€-363.02$ & $€-879.87$ & $€-3,001.07$ & $€-2,633.14$ & $€-1,952.33$ & $€-3,060.03$ \\
\hline F59D & $€ 938.76$ & $€ 703.65$ & $€-773.86$ & $€-106.35$ & $€ 205.14$ & $€-3,136.24$ \\
\hline
\end{tabular}

the radiology clinic receives the total DRG amount. However, this amount is reduced by the significant discounts in the case of a shorter length of stay which is most noticeable particularly in more complex, "more profitable" cases. Analysis of our data showed that up to $74 \%$ of cases in the F59D group were subject to a discount owing to the minimum length of stay requirement not being met. To date, consistent assurance that this limit is met has not been taken into account. A minimally invasive intervention often requires a significantly shorter length of stay than the length of stay that would be needed to receive the total DRG amount. The positive features of the minimally invasive approach for the patient, i. e., a short or very short length of stay, result in a decrease in profit for the hospital. Longer scheduled inpatient hospital stays only to meet the minimum length of stay requirement would not be fair to the patient, would seem implausible, and would not pass review by the Medical Service of the Health Funds.

Three (theoretical) measures for improving the profit situation are:

a) medically reasonable, low use of materials with simultaneous treatment of many "simple" cases (F59D)

b) consistent recording of secondary diagnoses resulting in the higher DRG amount for F59A that achieves a positive contribution margin

c) consistent assurance that the minimum length of stay requirement is met.
However, it must be noted that our university hospital is a maximum care hospital and patient selection according to severity cannot be readily performed and it is often difficult to meet the minimum length of stay requirement since the treatment has already been performed and no further measures in the inpatient setting will be performed (for example, mechanical rotational thrombectomy: first day of hospitalization on which a discount is to be applied in accordance with $\S 1$ paragraph 3 is the fourth day).

Shares from the InEK matrix such as the cost center "radiology" or "OP" as revenue for the radiology clinic are not sufficient to cover incurred costs. The fixed internal treatment charges based on the DKG-NT catalog provide even worse cost coverage. The reason for this is that the tariff catalog is outdated, does not represent radiological-interventional services in a differentiated manner, and the current costs for modern materials are not accurately taken into consideration [7]. In this connection, the development of alternative models to the ITCs based on DKG-NT previously used at our hospital is important and desirable: when for example the core service is performed by the interventional radiology department, but the department with beds receives the DRG payment, material costs for the intervention documented in the RIS per patient could be invoiced to the referring department. From the standpoint of radiology, the goal of an alternative ITC model is to also perform consultation services incurring material costs on the basis of fair compensation of the material costs incurred in the radiology department without raising the medical fee schedule point costs used in ITCs. For the fictitious redistribution of shares, it must be noted that, under consideration of the OP 
costs for the financing of interventional radiology, there is a certain distribution risk for patients in whom an additional surgical intervention would be performed during an inpatient hospital stay. In such a case, there would be undercompensation of the surgical department to the benefit of radiology. Since the patients evaluated in this study exclusively underwent endovascular treatment, this limitation does not apply to the results analyzed here.

In addition to complete restructuring of ITCs, the establishing of an own ward with beds or the co-use of interdisciplinary wards, e. g. for short-term patients, would be desired with respect to profits in interventional radiology in order to fundamentally improve economic issues.

The present study and its results have the following limitations: the number of cases per G-DRG is relatively low and generalization may only be possible on a limited basis. The evaluated scenarios are initially only valid for our hospital on an exemplary basis since different models can be used for internal treatment charges. A generalization for other interventional radiology departments is thus not possible or only with limitations since the situation can differ considerably from hospital to hospital in relation to ITCs. The use of materials and the associated costs also differ from hospital to hospital and thus the data are difficult to compare. Moreover, only data from a relatively short treatment period were used for the analysis.

\section{CLINICAL RELEVANCE}

- Under increasing economic pressure, it seems important from the standpoint of radiology to evaluate and optimize the revenue situation for PAD treatment.

- Internal treatment charges based on the DKG-NT in which radiology performs endovascular treatment for internal referring departments does not provide cost coverage at least in our maximum care hospital.

- The use of InEK shares as the basis for ITC model calculations also does not provide complete cost coverage under the indicated conditions. Positive contribution margins can only be achieved in these fictitious scenarios by receiving the complete DRG amount (e. g. for a department with beds).

- Creating fundamentally new ITC models or functioning as a department with its own beds seems desirable with regard to revenues in interventional radiology.

\section{Conflict of Interest}

The authors declare that they have no conflict of interest.

\section{References}

[1] Mendelson G, Aronow WS, Ahn C. Prevalence of coronary artery disease, atherothrombotic brain infarction, and peripheral arterial disease: associated risk factors in older Hispanics in an academic hospital-based geriatrics practice. J Am Geriatr Soc 1998; 46: 481- 483

[2] Kroger K, Stang A, Kondratieva J et al. Prevalence of peripheral arterial disease - results of the Heinz Nixdorf recall study. Eur J Epidemiol 2006; 21: $279-285$

[3] Bundesregierung D. Finanzierung, Versorgungsstrukturen und Versorgungsqualität im Krankenhausbereich nach Einführung der diagnosebezogenen Fallpauschalen (DRG). In. Berlin: Deutscher Bundestag; 2007

[4] Forbes JF, Adam DJ, Bell J et al. Bypass versus Angioplasty in Severe Ischaemia of the Leg (BASIL) trial: Health-related quality of life outcomes, resource utilization, and cost-effectiveness analysis. J Vasc Surg 2010; 51: 43S-51S

[5] Nolte-Ernsting C, Abel K, Krupski G et al. Economic evaluation of angiographic interventions including a whole-radiology in- and outpatient care. Fortschr. Röntgenstr 2006; 178: 78 - 89

[6] Chase MR, Friedman HS, Navaratnam P et al. Comparative Assessment of Medical Resource Use and Costs Associated with Patients with Symptomatic Peripheral Artery Disease in the United States. J Manag Care Spec Pharm 2016; 22: 667-675

[7] Strotzer M, Volk M, Lenhart M et al. Cost analysis of radiological interventional procedures and reimbursement within a clinic. Fortschr. Röntgenstr 2002; 174: 761 - 766

[8] Strotzer M, Feuerbach S, Volk M. Reimbursement of radiologically guided vascular interventions within the DRG-system: what will change? Fortschr. Röntgenstr 2004; 176: 1319-1325

[9] Goltz JP, Kleemann M. Complex recanalization techniques for complex femoro-popliteal lesions: how to optimize outcomes. J Cardiovasc Surg (Torino) 2015; 56: 31-41

[10] Rautio R, Keski-Nisula L, Paakkala T. Activity-based cost analysis in catheter-based angiography and interventional radiology. Eur Radiol 2003; 13: $1937-1945$

[11] Pietzsch JB, Geisler BP, Garner AM et al. Economic analysis of endovascular interventions for femoropopliteal arterial disease: a systematic -review and budget impact model for the United States and Germany. Catheter Cardiovasc Interv 2014; 84: 546-554 